Cite this article:

Jamilian A., Darnahal A. Eslami E., Kiaee B.

Kamali Z., Perillo L.

The Relationship between

Orthodontic Treatment Need

and Oral Health Related Quality

of Life of School Children.

Stoma Edu J. 2015;2(1):44-50

\section{THE RELATIONSHIP BETWEEN \\ ORTHODONTIC TREATMENT NEED \\ AND ORAL HEALTH RELATED QUALITY OF LIFE OF SCHOOL CHILDREN}

https://doi.org/10.25241/stomaeduj.2015.2(1).art.4

\section{Abdolreza Jamilian ${ }^{1 a^{*}}$, Alireza Darnahal ${ }^{16}$, Sara Eslami ic, Bita Kiaee ${ }^{1 d}$, Zinat Kamalie, Letizia Perillo ${ }^{4 f}$}

1.Department of Orthodontics, Tehran Dental Branch, Islamic Azad University, Tehran, Iran 2.Department of Orthodontics, Tehran dental branch, Islamic Azad University, Tehran, Iran 3.National Nutrition and Food Technology Research Institute, Faculty of Nutrition Sciences and Food Technology, Shahid Beheshti

University of Medical Sciences, Tehran, Iran 4.Post Graduate Orthodontic Program, Departments of Orthodontics, Second University of Naples, Naples, Italy

a., f.DDS, PhD, Professor b.d.DDS c. DDS, Assistant Professor e. MSc

Received: May, 7th 2015 Accepted: June, 1st 2015

* Corresponding author:

Professor Abdolreza Jamilian, DDS, PhD No 2713, Vali Asr St. Tehran 1966843133, Iran Tel: 0098-21-22011892; Fax: 0098-21-22022215 E-mail: info@jamilian.net

\title{
Abstract
}

Objective. The aim of this study was to assess the effect of different orthodontic treatment needs on the oral health-related quality of life of young people aged 15-17.

Methods. 684 ( 343 boys and 341 girls) school children aged 15 to 17 years were selected at random from 12 schools to represent the four main areas of Tehran. Malocclusion of the subjects was determined with the Dental Health Component (DHC) of Index of Orthodontic Treatment Need (IOTN). Participants also completed the shortened version Oral Health Impact Profile questionnaire (OHIP-14). Chi-Square test was used to analyze the data

Results. 41 of the subjects had previous orthodontic treatment or were being treated at the time of study. 413,172, and 58 of the subjects had little or no, borderline, and actual need for orthodontic treatment, respectively. Orthodontic treatment need significantly affected all daily activities in both male and female subjects.

Conclusions. Malocclusion has a negative impact on both physical and psychological aspects of the daily life of subjects who are in definite need for orthodontic treatment.

Keywords: orthodontic treatment need, oral health related quality of life, malocclusion, psychology

\section{Introduction}

Malocclusion in itself is neither a disease nor a life threatening condition; (1) nevertheless, the appearance of the mouth and a person's smile plays a significant role in judgments regarding facial attraction. Thus, malocclusion has large physical, social, and psychological impact on the individual and society.(24) Quality of life (QoL) has been defined by the World Health Organization as "people's perception of their position in life in the context of the culture and value systems in which they live and in relation to their goals, expectations, standards, and concerns."(5) Oral health-related quality of life (OHRQoL) is the extent to which oral and paraoral conditions impact one's life. Recently, researchers and clinicians have focused more on the patients' own perceptions of oral health status and oral health care systems to understand their needs, satisfaction with treatment, and ultimately the perceived overall quality of health systems. $(6,7)$ Understanding the impact of orthodontic treatment on quality of life is of great importance for many reasons. Informing the patients about the consequences and discomfort can lead to a better understanding. Informed consent gives the patients insight into the benefits and health gains associated with orthodontic treatment, which might help overcome problems associated with non-compliance.(8)

Recently, an Index of Treatment Need (IOTN) was proposed by Brook and Shaw(9) in the United Kingdom as a scoring system for estimating treatment need of patients with various degrees of malocclusion. The Dental Health Component (DHC) of the IOTN index places patients in five grades from "no need for treatment" to "extreme treatment 
Table 1. IOTN Treatment Grades

\section{Grade 5 (Extreme/Need treatment)}

$5 \bullet i \quad$ Impeded eruption of teeth (except for third molars) due to crowding, displacement, the presence of supernumerary teeth, retained deciduous teeth and any pathological cause.

$5 \bullet h \quad$ Extensive hypodontia with restorative implications (more than 1 tooth missing in any quadrant) requiring prerestorative orthodontics.

$5 \bullet a \quad$ Increased overjet greater than $9 \mathrm{~mm}$.

$5 \bullet \mathrm{m} \quad$ Reverse overjet greater than $3.5 \mathrm{~mm}$ with reported masticatory and speech difficulties.

$5 \bullet p \quad$ Defects of cleft lip and palate and other craniofacial anomalies.

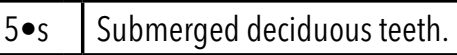

\section{Grade 4 (Severe/Need treatment)}

$4 \bullet h \quad$ Less extensive hypodontia requiring pre-restorative orthodontics or orthodontic space closure to obviate the need for a prosthesis.

$4 \bullet a \quad$ Increased overjet greater than $6 \mathrm{~mm}$, but less than or equal to $9 \mathrm{~mm}$.

$4 \bullet b \quad$ Reverse overjet greater than $3.5 \mathrm{~mm}$ with no masticatory or speech difficulties.

$4 \bullet \mathrm{m}$ Reverse overjet greater than $1 \mathrm{~mm}$ but less than $3.5 \mathrm{~mm}$ with recorded masticatory and speech difficulties.

$4 \bullet c \quad$ Anterior or posterior crossbites with greater than $2 \mathrm{~mm}$ discrepancy between retruded contact position and intercuspal $4 \bullet \mathrm{C}$ position.

$4 \bullet 1$ Posterior lingual crossbite with no functional occlusal contact in one or both buccal segments.

$4 \bullet \mathrm{d} \quad$ Severe contact point displacements greater than $4 \mathrm{~mm}$.

$4 \bullet$ Extreme lateral or anterior open bites greater than $4 \mathrm{~mm}$.

$4 \bullet f \quad$ Increased and complete overbite with gingival or palatal trauma.

$4 \bullet t \quad$ Partially erupted teeth, tipped and impacted against adjacent teeth.

$4 \bullet x \quad$ Presence of supernumerary teeth.

\section{Grade 3 (Moderate/Borderline need)}

$3 \bullet a \quad$ Increased overjet greater than $3.5 \mathrm{~mm}$, but less than or equal to $6 \mathrm{~mm}$ with incompetent lips.

$3 \bullet b \quad$ Reverse overjet greater than $1 \mathrm{~mm}$, but less than or equal to $3.5 \mathrm{~mm}$.

$3 \bullet \mathrm{c}$ Anterior or posterior crossbites with greater than $1 \mathrm{~mm}$, but less than or equal to $2 \mathrm{~mm}$ discrepancy between retruded

$3 \bullet \mathrm{C} \quad$ contact position and intercuspal position.

$3 \bullet \mathrm{d} \quad$ Contact point displacements greater than $2 \mathrm{~mm}$, but less than or equal to $4 \mathrm{~mm}$.

$3 \bullet$ e $\quad$ Lateral or anterior open bite greater than $2 \mathrm{~mm}$, but less than or equal to $4 \mathrm{~mm}$.

$3 \bullet \quad$ Deep overbite complete on gingival or palatal tissues, but no trauma.

\section{Grade 2 (Mild/Little Need)}

\begin{tabular}{|l|l|}
\hline $2 \bullet a$ & Increased overjet greater than $3.5 \mathrm{~mm}$, but less than or equal to $6 \mathrm{~mm}$ with competent lips. \\
\hline $2 \bullet b$ & Reverse overjet greater than $0 \mathrm{~mm}$ but less than or equal to $1 \mathrm{~mm}$. \\
\hline $2 \bullet c$ & $\begin{array}{l}\text { Anterior or posterior crossbite with less than or equal to } 1 \mathrm{~mm} \text { discrepancy between retruded contact position and } \\
\text { intercuspal position. }\end{array}$ \\
\hline $2 \bullet \mathrm{d}$ & Contact point displacements greater than $1 \mathrm{~mm}$ but less than or equal to $2 \mathrm{~mm}$. \\
\hline $2 \bullet e$ & Anterior or posterior open bite greater than $1 \mathrm{~mm}$ but less than or equal to $2 \mathrm{~mm}$. \\
\hline $2 \bullet f$ & Increased overbite greater than or equal to $3.5 \mathrm{~mm}$ without gingival contact. \\
\hline $2 \bullet \mathrm{g}$ & Pre- or post-normal occlusions with no other anomalies (includes up to half a unit discrepancy). \\
\hline $\mathbf{G r a d e} \mathbf{1}$ (No Need) \\
\hline $1 \bullet$ & Extremely minor malocclusions including contact point displacements less than $1 \mathrm{~mm}$. \\
\hline
\end{tabular}


Table 2. Characteristics and orthodontic treatment need of the subjects

\begin{tabular}{|c|ccc|}
\hline Sample & Men & Women & Total \\
\hline Number & 343 & 341 & 684 \\
\hline Age(Mean \pm SD) & $16 \pm 0.7$ & $16 \pm 0.8$ & $16 \pm 0.8$ \\
\hline IOTN 1 & 65 & 93 & 158 \\
\hline IOTN 2 & 146 & 109 & 255 \\
\hline IOTN3 & 76 & 96 & 172 \\
\hline IOTN 4 & 25 & 16 & 41 \\
\hline IOTN 5 & 10 & 7 & 17 \\
\hline $\begin{array}{c}\text { Previous Ortho } \\
\text { Treatment }\end{array}$ & 21 & 20 & 41 \\
\hline
\end{tabular}

need" (Table 1). The IOTN has problematic since some patients who have no psychosocial need for treatment would be perceived as requiring treatment. (12) The use of OHRQoL measures in addition to professional indices offers a potentially useful combination. Therefore, various studies have evaluated IOTN and its impact on OHRQoL. Masood et al (13) found that malocclusion has a significant negative impact on OHRQoL and its domains. Nevertheless, there was no reported difference in impact between male and females. Agou et al also found that the impact of malocclusion on quality of life is substantial in children with low self-esteem (14). Nevertheless, some other authors did not find any relationship between malocclusion or orthodontic treatment need and OHRQoL (15-17). Therefore, the aim of this study was to assess the effect of different orthodontic treatment needs on the OHRQOL of young adults.

\section{Material and Methods}

This study received approval from the Human Research Ethics Committee of the IAU University of medical sciences. Twelve schools were randomly selected among all high schools in the east, west, north, south, and center of Tehran (Iran) and a random sample of 684 (343 boys and 341 girls) aged 15-17 year-olds attending these schools was selected (30 to 35 subjects were randomly selected from each school). Parents of sampled children were notified about the purposes of the study.

Each patient was examined for orthodontic treatment need with IOTN. The examinations were conducted at school during the day, by one trained and calibrated dentist with the help of a tongue blade, mirror, probe and ruler; no radiographs were taken. The treatment needs of the patients were categorized as little or no treatment needed (IOTN 1 and 2), borderline need (IOTN 3), and definite need for treatment (IOTN 4 and 5). The subjects with previous orthodontic treatment were also categorized as a separate group. Examiner error was determined by re-examining 30 subjects after a period of at least two weeks. The error was non-significant. The subjects were also asked to complete questionnaires incorporating the Short
Form Oral Health Impact Profile measure (OHIP-14, a generic oral health-related QoL assessment).(18) The OHIP is designed to determine the perception of the social impact of oral disorders and has well-documented psychometric properties.(19) Responses to the 14 items of OHIP were recorded in a 5 -point Likert scale $(0=$ never, $1=$ hardly ever, 2 = occasionally, 3 = fairly often, 4 = very often). The responses were dichotomized as "impact" and "no impact". The responses of "never" and "hardly ever" were considered as "no impact" and "occasionally", "fairly often", and "very often" were considered as at least some oral health "impact". The Statistical Package for Social Sciences, Version 20 (SPSS Inc. Chicago, Illinois, USA) was used to analyze the data. Chi-Square test was used to analyze the data and $p$-value was set at $P<0.05$.

\section{Results}

A total of 684 students (mean age $16 \pm 0.8$ years) from 12 secondary schools were examined. Table 2 shows that the samples included 343 male and 341 female subjects. Table 2 also shows the detailed distribution of subjects based on their IOTN grades. As can be seen in table 3, daily activities were associated with higher orthodontic treatment needs in both male and female subjects. Almost none of the subjects with no or little treatment need and borderline treatment need had problem pronouncing words; while $26 \%$ of the male students and $30 \%$ of the female students of the definite need for treatment group had problem pronouncing words. $(P<0.001)$ About $70 \%$ of the female subjects and $43 \%$ of the male subjects of the definite need for treatment group felt tense in their life; while, only $5 \%$ of the male subjects and $4 \%$ of the female subjects of the no or little treatment need group felt tense. Chi-square test showed that all daily activities were significantly affected by the treatment need.

\section{Discussion}

This study showed that malocclusion has both physical and psychological impacts on male and female subjects who are in definite need for orthodontic treatment. The findings of this study corresponds with the study conducted by Hassan and Amin Hel (20). Their study results highlighted 
Table 3. Impacts on daily activities according to orthodontic treatment needs

\begin{tabular}{|c|c|c|c|c|c|c|c|c|}
\hline & \multicolumn{2}{|c|}{$\begin{array}{l}\text { No or little } \\
\text { treatment need }\end{array}$} & \multicolumn{2}{|c|}{$\begin{array}{l}\text { Borderline } \\
\text { treatment need }\end{array}$} & \multicolumn{2}{|c|}{$\begin{array}{c}\text { Definite need for } \\
\text { treatment }\end{array}$} & \multicolumn{2}{|c|}{$P$ value } \\
\hline & $\begin{array}{l}\text { Male } \\
\mathrm{N}=211\end{array}$ & $\begin{array}{l}\text { Female } \\
\mathrm{N}=202\end{array}$ & $\begin{array}{l}\text { Male } \\
\mathrm{N}=76\end{array}$ & $\begin{array}{l}\text { Female } \\
\mathrm{N}=96\end{array}$ & $\begin{array}{l}\text { Male } \\
\mathrm{N}=35\end{array}$ & $\begin{array}{l}\text { Female } \\
\mathrm{N}=23\end{array}$ & Male & Female \\
\hline \multicolumn{9}{|c|}{$\begin{array}{l}\text { Had problem pronouncing } \\
\text { words }\end{array}$} \\
\hline No impact & $206(98)$ & $200(99)$ & $75(99)$ & $94(98)$ & $26(74)$ & $16(70)$ & \multirow{2}{*}{0.001} & \multirow{2}{*}{0.001} \\
\hline Impact & $5(2)$ & $2(1)$ & $1(1)$ & $2(2)$ & $9(26)$ & $7(30)$ & & \\
\hline \multicolumn{9}{|c|}{$\begin{array}{c}\text { Felt sense of taste } \\
\text { worsened }\end{array}$} \\
\hline No impact & $203(96)$ & 201 (99) & $68(89)$ & $94(98)$ & $22(63)$ & $11(48)$ & \multirow{2}{*}{0.001} & \multirow{2}{*}{0.001} \\
\hline Impact & $8(4)$ & $1(1)$ & $8(11)$ & $2(2)$ & $13(37)$ & $12(52)$ & & \\
\hline \multicolumn{9}{|c|}{$\begin{array}{c}\text { Had painful aching } \\
\text { in mouth }\end{array}$} \\
\hline No impact & $200(95)$ & $191(94)$ & $68(89)$ & $81(84)$ & $18(51)$ & $9(39)$ & \multirow{2}{*}{0.001} & \multirow{2}{*}{0.001} \\
\hline Impact & $11(5)$ & $11(6)$ & $8(11)$ & $15(16)$ & $17(49)$ & $14(61)$ & & \\
\hline \multicolumn{9}{|c|}{$\begin{array}{l}\text { Found it } \\
\text { uncomfortable to eat } \\
\text { food }\end{array}$} \\
\hline No impact & $199(94)$ & $192(95)$ & $67(88)$ & $86(89)$ & $18(51)$ & $7(30)$ & \multirow{2}{*}{0.001} & \multirow{2}{*}{0.001} \\
\hline Impact & $12(6)$ & $10(5)$ & $9(12)$ & $10(11)$ & $17(49)$ & $16(70)$ & & \\
\hline \multicolumn{9}{|c|}{$\begin{array}{l}\text { Have been self- } \\
\text { conscious }\end{array}$} \\
\hline No impact & $197(93)$ & $186(92)$ & $69(90)$ & $75(78)$ & $21(60)$ & $10(43)$ & \multirow{2}{*}{0.001} & \multirow{2}{*}{0.001} \\
\hline Impact & $14(7)$ & $16(8)$ & $7(10)$ & $21(22)$ & $14(40)$ & $13(57)$ & & \\
\hline \multicolumn{9}{|l|}{ Felt tense } \\
\hline No impact & $200(95)$ & $194(96)$ & $68(89)$ & $85(88)$ & $20(57)$ & $7(30)$ & \multirow{2}{*}{0.001} & \multirow{2}{*}{0.001} \\
\hline Impact & $11(5)$ & $8(4)$ & $8(11)$ & $11(12)$ & $15(43)$ & $16(70)$ & & \\
\hline \multicolumn{9}{|c|}{$\begin{array}{c}\text { Had an } \\
\text { unsatisfactory diet }\end{array}$} \\
\hline No impact & $210(99)$ & 201 (99) & $69(90)$ & $96(100)$ & $23(66)$ & $9(39)$ & \multirow{2}{*}{0.001} & \multirow{2}{*}{0.001} \\
\hline Impact & $1(1)$ & $1(1)$ & $7(10)$ & $0(0)$ & $12(44)$ & $14(61)$ & & \\
\hline \multicolumn{9}{|c|}{$\begin{array}{l}\text { Had to interrupt } \\
\text { meals }\end{array}$} \\
\hline No impact & $208(98)$ & $198(98)$ & $70(92)$ & $92(96)$ & $22(63)$ & $7(30)$ & \multirow{2}{*}{0.001} & $0 \cap 001$ \\
\hline Impact & $3(2)$ & $4(2)$ & $6(8)$ & $4(4)$ & $13(37)$ & $16(70)$ & & 0.001 \\
\hline $\begin{array}{l}\text { Found it difficu } \\
\text { relax }\end{array}$ & & & & & & & & \\
\hline No impact & $203(96)$ & $196(97)$ & $74(97)$ & $88(91)$ & $19(54)$ & $9(39)$ & $0 \cap 01$ & 0001 \\
\hline Impact & $8(4)$ & $6(3)$ & $2(3)$ & $8(9)$ & $16(46)$ & $14(61)$ & 0.001 & 0.001 \\
\hline $\begin{array}{l}\text { Have been a I } \\
\text { embarrasse }\end{array}$ & & & & & & & & \\
\hline No impact & $202(95)$ & $194(96)$ & $64(84)$ & $84(87)$ & $20(57)$ & $12(52)$ & 0 ○ी & م001 \\
\hline Impact & $9(5)$ & $8(4)$ & $12(16)$ & $12(13)$ & $15(43)$ & $11(48)$ & 0.001 & 0.001 \\
\hline $\begin{array}{r}\text { Have been irrit } \\
\text { with people }\end{array}$ & & & & & & & & \\
\hline No impact & $207(98)$ & $200(99)$ & $7193)$ & $90(93)$ & $19(54)$ & $7(30)$ & $0 \cap 01$ & ח 001 \\
\hline Impact & $4(2)$ & $2(1)$ & $5(7)$ & $6(7)$ & $16(46)$ & $16(70)$ & 0.001 & 0.001 \\
\hline
\end{tabular}




\begin{tabular}{|c|c|c|c|c|c|c|c|c|}
\hline $\begin{array}{c}\text { Had difficulty doing } \\
\text { useful jobs }\end{array}$ & & & & & & & & \\
\hline No impact & $207(98)$ & $199(98)$ & $66(86)$ & $95(99)$ & $19(54)$ & $10(43)$ & & \\
\hline Impact & $4(2)$ & $3(2)$ & $10(14)$ & $1(1)$ & $16(46)$ & $13(57)$ & 0.001 & 0.001 \\
\hline \multicolumn{9}{|l|}{$\begin{array}{l}\text { Felt life in general } \\
\text { less satisfactory }\end{array}$} \\
\hline No impact & $207(98)$ & $200(99)$ & $70(92)$ & $91(95)$ & $22(63)$ & $8(35)$ & \multirow{2}{*}{0.001} & \multirow{2}{*}{0.001} \\
\hline Impact & $4(2)$ & $2(1)$ & $6(8)$ & $5(5)$ & $13(37)$ & $15(65)$ & & \\
\hline \multicolumn{9}{|l|}{$\begin{array}{l}\text { Have been unable to } \\
\text { function }\end{array}$} \\
\hline No impact & $207(98)$ & $199(98)$ & $76(100)$ & $96(100)$ & $23(66)$ & $11(48)$ & \multirow{2}{*}{0.001} & \multirow{2}{*}{0.001} \\
\hline Impact & $4(2)$ & $3(2)$ & $0(0)$ & $0(0)$ & $12(44)$ & $12(52)$ & & \\
\hline
\end{tabular}

the impact of malocclusion on OHRQoL of young adults and emphasize the importance of patient-based evaluation of oral health status and oral health needs. However, they showed that orthodontic treatment needs did not significantly affect speech and word pronunciation. While similar to our study other researchers observed a strong association between speech disorders and dentofacial abnormalities (21-24). The difference between this study and the study conducted by Hassan and Amin Hel (20) might be the difference between the ages of the subjects since in their study the subjects were 21 to 25 years old. In a wider age range Masood et al (13) assessed OHRQoL in young people aged 15-25, and the association between IOTN, sex, age and education level, and OHRQoL. Similar to our study, they found that malocclusion has a significant negative impact on OHRQoL and its domains. Likewise, they reported no difference in impact between males and females. With respect to the gender differences, the findings of our study were in contradiction with the study of de Oliveria and Sheiham (25), who reported that sex significantly affects the impact of

\section{Bibliography}

References:

1. Mohlin B, al-Saadi E, Andrup L, Ekblom K. Orthodontics in 12-year old children. Demand, treatment motivating factors and treatment decisions. Swed Dent J. 2002;26(2):89-98.

2. Liu Z, McGrath C, Hägg U. The impact of malocclusion/orthodontic treatment need on the quality of life. A systematic review. Angle Orthod. 2009;79(3):585-591.

3. van Wyk PJ, Drummond RJ. Orthodontic status and treatment need of 12-year-old children in South Africa using the Dental Aesthetic Index. SADJ. 2005;60(8):334-336, 338.

4. Perillo L, Femminella B, Farronato D, Baccetti T, Contardo L, Perinetti G. Do malocclusion and Helkimo Index $\geq$ correlate with body posture? J Oral Rehabil. 2011;38(4):242-252. malocclusion on OHRQOL, and women were 1.22 times more likely to have an impact than men.

Both IOTN and OHIP-14 are reliable instruments; nevertheless, they have some limitations. One of the major limitations of OHIP-14 is that it does not elicit the specific cause(s) of the impacts recorded, which can be related to a variety of oral health conditions and not necessarily the subject's malocclusion. IOTN may be a relatively insensitive instrument to measure minor occlusal traits and irregularities which mostly affect patient appearance and about which a patient is deeply concerned (26).

\section{Conclusions}

Malocclusion has a negative impact on both physical and psychological aspects of the daily life of subjects who are in definite need for orthodontic treatment. These impacts are similar for both male and female subjects.

\section{Conflict of Interest and Sources for Funding: No}

5. The World Health Organization Quality of Life assessment (WHOQOL): position paper from the World Health Organization. Soc Sci Med. 1995;41(10):1403-1409.

6. Barbosa TS, Gavião MB. Oral health-related quality of life in children: part II. Effects of clinical oral health status. A systematic review. Int J Dent Hyg. 2008;6(2):100-107.

7. Ballini A, Cantore S, Fatone L, Montenegro V, De Vito D, Pettini F, Crincoli V, Antelmi A, Romita P, Rapone B, Miniello G, Perillo L, Grassi FR, Foti C. Transmission of nonviral sexually transmitted infections and oral sex. J Sex Med. 2012;9(2):372384. 8. Sergl HG, Klages U, Zentner A. Pain and discomfort during orthodontic treatment: causative factors and effects on compliance. Am J Orthod Dentofacial Orthop. 1998;114(6):684-691. 
9. Brook PH, Shaw WC. The development of an index of orthodontic treatment priority. Eur J Orthod. 1989;11(3):309-320.

10. Perillo L, Masucci C, Ferro F, Apicella D, Baccetti T. Prevalence of orthodontic treatment need in southern Italian schoolchildren. Eur J Orthod. 2010;32(1):49-53.

11. Jamilian A, Toliat M, Etezad S. Prevalence of malocclusion and index of orthodontic treatment need in children in Tehran. Oral Health Prev Dent. 2010;8(4):339-343.

12. Kok YV, Mageson P, Harradine NW, Sprod AJ. Comparing a quality of life measure and the Aesthetic Component of the Index of Orthodontic Treatment Need (IOTN) in assessing orthodontic treatment need and concern. J Orthod. 2004;31(4):312-318; discussion 300-1.

13. Masood Y, Masood M, Zainul NN, Araby NB, Hussain SF, Newton T. Impact of malocclusion on oral health related quality of life in young people. Health Qual Life Outcomes. 2013;11:25.

14. Agou S, Locker D, Streiner DL, Tompson B. Impact of self-esteem on the oral-health-related quality of life of children with malocclusion. Am J Orthod Dentofacial Orthop. 2008;134(4):484-489. 15. O'Brien C, Benson PE, Marshman Z. Evaluation of a quality of life measure for children with malocclusion. J Orthod. 2007;34(3):185-193; discussion 76.

16. de Oliveira CM, Sheiham A, Tsakos G, O'Brien KD. Oral health-related quality of life and the IOTN index as predictors of children's perceived needs and acceptance for orthodontic treatment. Br Dent J. 2008;204(7):1-5; discussion 384-385.

17. Zhang $M$, McGrath $C$, Hägg U. The impact of malocclusion and its treatment on quality of life: a literature review. Int J Paediatr Dent. 2006;16(6):381-387.

18. Ravaghi $V$, Farrahi-Avval N, Locker D, Underwood M. Validation of the Persian short version of the Oral Health Impact Profile (OHIP-14). Oral Health Prev Dent. 2010;8(3):229-235.

19. Slade GD. Assessing change in quality of life using the Oral Health Impact Profile. Community Dent Oral Epidemiol. 1998;26(1):52-61.

20. Hassan AH, Amin Hel-S. Association of orthodontic treatment needs and oral healthrelated quality of life in young adults. Am J Orthod Dentofacial Orthop. 2010;137(1):42-47.

21. VallinoLD, Tompson B.Perceptual characteristics of consonant errors associated with malocclusion. J Oral Maxillofac Surg. 1993;51(8):850-856.

22. Pahkala R, Laine T, Narhi M. Associations among different orofacial dysfunctions in 9-11-year-olds. Eur J Orthod. 1995;17(6):497-503.

23. Perillo L, Castaldo MI, Cannavale R, Longobardi A, Grassia V, Rullo R, Chiodini P. Evaluation of longterm effects in patients treated with Frankel-2 appliance. Eur J Paediatr Dent. 2011;12(4):261266.

24. Jamilian A, Perillo L, Rosa M. Missing upper incisors: a retrospective study of orthodontic space closure versus implant. Prog Orthod. 2015;16(1):2. 25. de Oliveira CM, Sheiham A. Orthodontic treatment and its impact on oral healthrelated quality of life in Brazilian adolescents. J Orthod. 2004;31(1):20-27; discussion 15. 26. Bernabé E, Sheiham A, Tsakos G, Messias de Oliveira $C$. The impact of orthodontic treatment on the quality of life in adolescents: a case-control study. Eur J Orthod. 2008;30(5):515-520. 
Abdolreza Jamilian,

DDS, PhD, Professor Department of Orthodontics, Tehran Dental Branch, Islamic Azad University,

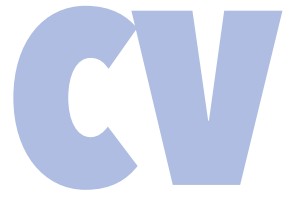

Prof. Jamilian is an orthodontic specialist. He was certified by the European Board of Orthodontics in 2013. He is now a professor at the Islamic Azad University, dental branch in Tehran, fellow of Orthognathic surgery and craniofacial syndromes, and a member of the cranimaxilloofacial research center. His practice is limited to orthodontics. He has lectured in several international congresses and has been a consultant for various journals.

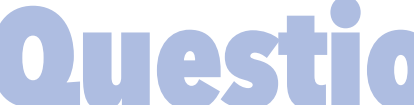

\section{How does malocelusion affect the life of the patients?}

$\square$ a. It has negative effects on physical aspects of their daily life

b. It has negative effects on psychological aspects of their daily life

a. a \& b similar for both male and female subjects

$\square$ d. a \& b different between male and female subjects.

\section{Which grade of IOTN is in extreme need for treatment?}

a. Grade 5

b. Grade 3

ac. Grade 2

$\square$ d. Both $a$ and $b$

\section{How many people were in the study?}

口a. 864

b. 684

c. 486

$\square$ d. None of them

\section{Increased overjet greater than $9 \mathrm{~mm}$ is categorized as which grade of IOTw?}

a. Grade 3

ab. Grade 4

ac. Grade 5

$\square d$. all of the above 